\title{
Modelling tunable band-pass filters based on RF-MEMS Metamaterials
}

\author{
Marta Morata ${ }^{(1)}$, Ignacio Gil ${ }^{(2)}$, Raúl Fernández-García ${ }^{(2)}$ \\ (1) Escuela Universitaria Salesiana de Sarriá (EUSS),Pg Sant Joan Bosco 74 \\ 08017 -Barcelona (Spain) \\ (2) \\ Department of Electronic Engineering, Universitat Politècnica de Catalunya, Terrassa
}

(Barcelona), 08222, (Spain)

\begin{abstract}
This work describes progress toward designing and modelling reconfigurable band-pass filters based on RF microelectromechanical systems (RF-MEMS) metamaterials. A device consisting of a coplanar waveguide (CPW) structure that combines complementary split ring resonators (CSRRs) and RF-MEMS varactor bridges, operating at $\mathrm{K}$ and $\mathrm{Ka}$-band, is proposed. Several layouts have been designed and electromagnetically (EM) simulated. A full equivalent circuit model for the description of the proposed structure, including transmission lines, RF-MEMS, subwavelength resonators and coupling parameters, is provided. A high degree of accuracy between EM simulations behaviour and electrical model has been obtained.
\end{abstract}

KEY WORDS: RF-MEMS; reconfigurable filters; complementary split rings resonators (CSRRs); metamaterials; electromagnetic simulation; electrical model.

\section{INTRODUCTION}

The research on reconfigurable band-pass filters based on RF-MEMS bridges has increased significantly in the last years due to the good performance of RFMEMS as switches and varactors. In fact, RF-MEMS present very low loss, high$Q$ and outstanding linearity [1]. These devices are typically implemented by several lithographic steps which perform RF-MEMS in conventional transmission lines. Typically, RF-MEMS filters design are carried out by loading a transmission line (TL) periodically with RF-MEMS bridges, forming a distributed MEMS TL [2]. Alternatively, metamaterial transmission lines (i.e., artificial lines consisting of a host line loaded with reactive elements) have been revealed as good candidates in order to improve the performance of conventional microwave filters [3]. 
Recently, several tunable band-pass filters based on metamaterials have been developed in PCB [4]. Efficient electrical models of microwave components and devices are crucial in order to design filter implementations in many areas such as signal processing, wireless communications or biomedical engineering. According to the state of the art, several works have been developed to achieve accurate electrical models in order to reproduce frequency responses of RFMEMS tunable filters [5] and tunable metamaterial transmission lines in PCB [6]. To the best knowledge of the authors, some few works have presented the combination of RF-MEMS and metamaterials in with the aim to implement reconfigurable filters $[7,8]$.

In this paper, we present the first full electrical model of tunable band-pass filters based on RF-MEMS and complementary split ring resonators (CSRRs) [9]. Such particles are metamaterial subwavelength resonators which properly combined with shunt metallic wires produce a band-pass frequency response. A unit-cell based on a coplanar waveguide structure (CPW) loaded with CSRRs and combined with the embedded RF-MEMS varactor, is proposed in order to design and model such as tunable filters.

The paper is organized as follows: Section 2 introduces the topology of the bandpass filter based on RF-MEMS metamaterials. The proposed electrical model of the filter is addressed in Section 3, whereas the comparison between the EM simulations and model are discussed in Section 4. Finally the conclusion is given in Section 5.

\section{RF-MEMS METAMATERIAL UNIT-CELL TOPOLOGY}

Fig. 1 shows the layout of the proposed CSRR/RF-MEMS unit-cell and its relevant dimensions. The device consists of a $50 \Omega$ CPW structure loaded with 3 rectangular CSRRs located in its central strip, up and down ground planes together with an embedded RF-MEMS varactor bridge (actuating as reconfigurable device). According to the theory, CSRRs etched in the central strip or the ground planes provide a negative effective permittivity $(\varepsilon<0)$. According to Maxwell's equations, another element presenting negative effective permeability is required in order to achieve propagation (i.e. $\varepsilon<0$ and $\mu<0$ to obtain a band-pass frequency response) [10]. The elements which provide $\mu<0$ are two metal wires connecting the central CPW strip and the ground planes. The RF-MEMS bridge is situated over the central ring and anchored on the substrate by means of two holes in both ground planes, located in the center of the up and down CSRRs. The CSRRs present an LC-tank behavior and are electrically coupled to the host line. Tuning is achieved thanks to the actuation on the RFMEMS, which modifies the electrical characteristics of the CSRRs and the electric coupling (i.e. the effective resonance frequency). The dimensions of the proposed unit-cell correspond to (in reference to Fig. 1): the up, down and central 
CSRRs: $C=d=10 \mu \mathrm{m}, \mathrm{W}=130 \mu \mathrm{m}, \mathrm{l}=660 \mu \mathrm{m}$; CPW dimensions are: $\mathrm{W}=150 \mu \mathrm{m}$ and $\mathrm{G}=30 \mu \mathrm{m}$. The RF-MEMS is defined by $\mathrm{B}=80 \mu \mathrm{m}, \mathrm{b}=100 \mu \mathrm{m}, \mathrm{h}=40 \mu \mathrm{m}$ and $\mathrm{H}=380 \mu \mathrm{m}$. The metal wires width connecting the central CPW strip and the ground planes, are $10 \mu \mathrm{m}$. The overall unit-cell length is $L=760 \mu \mathrm{m}$. The gap between the bridge and the substrate is $2 \mu \mathrm{m}$ when the bridge is in the up-state. Under DC bias, bridge is moved to the down-state and the gap corresponds to $0,5 \mu \mathrm{m}$. Fig. 2 defines an example of a 2-stage band-pass filter constituted by the proposed unit-cell. The distance between adjacent CSRRs is $90 \mu \mathrm{m}$.

In order to implement the RF-MEMS, a stripped-down technology based on three photolithographic levels masks is necessary [10]. A $1 \mu \mathrm{m}$ thick Al layer is sputterdeposited and patterned on a $650 \mu \mathrm{m}$ thick glass substrate (AF45) with a relative permittivity constant $\varepsilon_{r}=3,9$ to define the CPW structures. The CSRRs have been performed by etching the central strip of the CPW and the corresponding ground planes. Then a $3 \mu \mathrm{m}$ thick sacrificial photoresist layer is deposited and patterned to define the anchoring regions of the bridges structures. Before a second Al layer is deposited and patterned in the same condition as the first one. Then, the MEMS beams are defined when the sacrificial photoresist is etched to release the structures.

\section{ELECTRICAL MODEL}

The lumped-element equivalent-circuit model which describes the behavior of the CSRRs/RF-MEMS unit-cell is depicted in Fig. 3. The RF-MEMS bridges are modeled by means of a lumped RLC circuit, where $C_{m}$ corresponds to a variable capacitance (having an up-state and a down-state value), $L_{m}$ is the bridge inductance and the resistor $R_{m}$ involves the microelectromechanical system losses. Since the bridge is anchored in both ground holes, two capacitances $\left(\mathrm{C}_{\mathrm{a}}\right)$ describe the electric coupling between the RF-MEMS anchoring and RF ground. The CPW line is described by means of the per-section inductance, L, and capacitance, $C$ (the actual value must be slightly corrected due 0 the coupling with the CSRR). All the etched CSRRs are modelled by means of a parallel LC tank, $L_{C}$ and $C_{C}$ being the reactive elements that perform the intrinsic resonance frequency of the resonators and $R_{C}$ takes into account the eventual losses associated with the resonators. The central CSRRs is directly connected to the host line and electrically coupled to the capacitance of the RF-MEMS. The up and down etched CSRRs are connected to the ground planes and electrically coupled to the host line through the slot capacitance of the CPW, $\mathrm{C}_{\text {ma. }}$. Finally, the metal wires connecting the central CPW strip and the ground planes present and inductive response, and are modeled by means of the inductance, $\mathrm{L}_{\mathrm{a}}$. Therefore, the intrinsic resonance frequency of the subwavelength resonators is directly affected by the RF-MEMS actuation. In fact, when $C_{M}$ is tuned the electrical properties of CSRRs are modified so that their resonance frequency. 
In order to extract the different parameters of the electrical model, the problem is analyzed sequentially due to the high number of involved variables. The parameters have been extracted by means of $2.5 \mathrm{D}$ electromagnetic simulations performed with the Agilent Momentum simulator and the Agilent Advanced Design System software. First, the CPW reactive elements, $L$ and $C$, can be extracted by means of a conventional transmission line calculator (Agilent Line Calc). Second, an electromagnetic simulation of the AF45 glass substrate (using the commercial Agilent Momentum) is performed by taking into account the layout of the CSRR etched in the CPW (with no RF-MEMS). The evaluation of the resonance frequency of the CSRR (tank $L_{C} C_{C}$ ) has been used in order to determine the value of its reactive elements, according (1),

$$
f_{o}=\frac{1}{2 \pi \sqrt{L_{C} C_{C}}} .
$$

On the other hand, $\mathrm{C}_{\mathrm{M}}$ can be estimated in a first approximation by the wellknown parallel plate capacitance equation [1]. An effective cross area of the RFMEMS has been considered, since the CPW strip is etched in order to perform the CSRRs particles. Finally, $C_{M}$ and $L_{M}$ have been determined from full-wave simulation of the CPW/RF-MEMS (with no CSRRs) layout. The losses of the bridge have been estimated by means of $R_{M}$ [1]. Since the actual RF-MEMS device is anchored directly on the substrate in holes of the CPW ground planes, the anchoring capacitance, $\mathrm{C}_{\mathrm{a}}$, is estimated by considering the distributed capacitance formed by the ground plane and the floating anchor of the bridge. $\mathrm{C}_{\mathrm{ma}}$ and $\mathrm{L}_{\mathrm{a}}$ are also electromagnetically simulated (by using two ports between ground plane-host line and metal wires, respectively) in order to obtain their equivalent values by comparison with capacitive and inductive equivalent circuit response. The second order parasitic capacitances and inductances which can affect at frequencies above resonance frequency have not been included in the model for simplicity.

Table I summarizes the extracted model parameters according to the previous procedure. Note that two values for $\mathrm{C}_{\mathrm{C}}$ and $\mathrm{C}_{\mathrm{ma}}$ have been considered, $\mathrm{C}_{\mathrm{CU}}, \mathrm{C}_{\mathrm{maU}}$ and $\mathrm{C}_{\mathrm{CD}}, \mathrm{C}_{\mathrm{maD}}$ for the up and down MEMS state (modeled by means of $\mathrm{C}_{\mathrm{MU}}$ and $\mathrm{C}_{\mathrm{MD}}$, respectively). This fact is due to the actual distributed capacitance of the RF-MEMS which modifies the electrical characteristics of the CSRRs and electric coupling between the host line and the CSRRs, with the result of significant tuning of the allowed band. Therefore, $\mathrm{C}_{M}$ is mainly coupled to the CSRR, but a significant contribution to the host line is produced in the down state, and therefore a high effective value of $\mathrm{C}_{\mathrm{CD}}>\mathrm{C}_{\mathrm{CU}}$ and $\mathrm{C}_{\mathrm{maD}}>\mathrm{C}_{\mathrm{maU}}$ are observed. Finally, due to the distributed geometry, the capacitive interaction between the RF-MEMS and the CSRRs etched in the ground plane has been neglected. 


\section{ELECTROMAGNETIC SIMULATIONS VERSUS ELECTRICAL RESPONSE}

In order to validate the proposed lumped model we have compared the electric simulations of the CSRR/RF-MEMS filter versus the corresponding layout electromagnetic simulations. This procedure has been validated experimentally by the authors in [8]. Layout simulation has been carried out by considering planar plate heights of $0.5 \mu \mathrm{m}$ (down-state) and $2 \mu \mathrm{m}$ (up-state), respectively and losses have been assumed (by means of the parameters $R_{M}$ and Rc). Fig. 4 and 5 show the comparison between electromagnetic simulations and the proposed lumped model insertion and return losses (S21, S11). A processing timeconsuming of $0.6 \mathrm{~s}$ and $267.3 \mathrm{~s}$ have been required for electrical and electromagnetic simulations, respectively, on a dual $\mathrm{CPU} 3 \mathrm{GHz}$ Pentium. As expected, the structure exhibits band pass behavior with tuning capability. The simulated frequency range corresponds to 24.9-32.7 $\mathrm{GHz}$ ( $\mathrm{K}$ and Ka-band), which implies a tuning range of roughly $27 \%$. Electromagnetic simulated rejection level and fractional bandwidth are $\mathrm{IL}=-3.8 \mathrm{~dB}, \Delta \mathrm{f}=5.6 \%$ (down state) and $\mathrm{IL}=-4.3$ $\mathrm{dB}, \Delta \mathrm{f}=7 \%$ (up state) and same values are predicted through the 1 -stage band pass model. In fact, the lumped model reproduces the band pass response with a good accuracy, including the following transmission zero. With regard to return losses, the model correctly fits the involved resonance frequencies. The mismatch between the return losses is due to the intrinsic ideality of the lumped model.

The presented model has been used in order to design a 2-stage band-pass filter (Fig. 2) by using the same parameters summarized in Table I. Fig. 6 illustrates the frequency response comparison between electromagnetic and model simulations. It can be observed a significant matching of the results and an equivalent frequency range with regard to the 1-stage design. In this case, In this case, electromagnetic simulated rejection level and fractional bandwidth correspond to $\mathrm{IL}=-7 \mathrm{~dB}, \Delta \mathrm{f}=4.4 \%$ (down state) and $\mathrm{IL}=-8.7 \mathrm{~dB}, \Delta \mathrm{f}=4.6 \%$ (up state). As result, it has been demonstrated that the presented model accurately describes the behavior of CSRR/RF-MEMS filters up to resonance frequency in both cases (up and down) and the design methodology can be used in order to design such structures.

\section{CONCLUSIONS}

In summary, an electrical model for tunable band pass filters based on the combination of complementary split ring resonators and RF-MEMS switchable capacitors has been presented. A high degree of accuracy of the model up to the resonance frequency has been demonstrated by comparison with layout 
electromagnetic simulations. The design methodology can be applied to develop CSRR/RF-MEMS filters. This work opens the door to the design of microwave and millimeter band pass filters based on the combination of RF-MEMS and metamaterial-based technologies.

\section{ACKNOWLEDGEMENTS}

This work has been supported by the Spanish-MICINN under projects TEC200909994, TEC2010-18550 and AGAUR 2009 SGR 1425.

\section{REFERENCES}

[1] G.M. Rebeiz, "RF MEMS: Theory, Design and Technology", John Wiley \& Sons, 2003.

[2] K. Entesari and G.M. Rebeiz, "A 12-18 GHz three-pole RF MEMS tunable filter", IEEE Transactions on Microwave Theory and Techniques, vol. 53, pp. 2566-2571, August 2005.

[3] J. Bonache, I. Gil, J. García-García, F. Martín, "Novel Microstrip Band Pass Filters Based on Complementary Split Rings Resonators", IEEE Transactions on Microwave Theory and Techniques, vol. 54, pp. 265-271, January 2006.

[4] A.S. Mohra and O.F. Siddiqui, "Tunable bandpass filter based on capacitorloaded metamaterial lines", Electronics Letters, vol. 45, pp. 470-472, April 2009.

[5] K. Entesari, K. Obeidat, A.R. Brown and G.M. Rebeiz, "A 25-75 MHz RF MEMS tunable filters", IEEE Transactions on Microwave Theory and Techniques, vol. 55, pp. 2399-2405, November 2007.

[6] I. Gil, J. Bonache, J. García and F. Martín, "Tunable metamaterial transmission lines on varactor-loaded split ring resonators", IEEE Transactions on Microwave theory and Techniques, vol. 54,no.6, pp. 2665-2674, June 2006.

[7] I. Gil, X. Rottenberg, W. D. Raedt and F. Martin, "Tunable stop-band filter at Q-band based on RF-MEMS metamaterials", Electronics Letters, vol. 43, pp. 1153-1154, October 2007.

[8] I. Gil, M. Morata, R. Fernández, X. Rottenberg, W. De Raedt. "Characterization and modelling of switchable stop-band filtres base don RFMEMS and complementary splits ring resonators", Microelectronics Engineering, accepted.

[9] F. Falcone, T. Lopetegi, J.D. Baena, E. Marqués, F. Martín and M. Sorolla, "Effective negative- $\varepsilon$ stop-band microstrip lines based on complementary split ring resonators", IEEE Microwave and Wireless Component Letters, vol. 14, pp. 280-282, June 2004. 
[10] V.G. Veselago, "The electrodunamics of substances with simultaneously negayive values of $\varepsilon$ and $\mu$ ", Sov. Phys.-Usp., vol. 10, pp. 509-514, Jan.-Feb. 1968.

[11] X.Rottenberg, S.Brebels, P.Ekkels, P.Czarnecki, P.Mertens, B.Nauwelaers, R.Puers, I.De Wolf, W.De Raedt and H.A.C.Tilmens. "Electrostatic Fringing-Field Actuator (EFFA): Application towards a Low-Complexity Thin-Film RF-MEMS technology", J.Micromech.Microeng. 17 (2007) S204 - S210. 


\section{FIGURE CAPTIONS AND TABLES}

Fig. 1. Layout of the proposed band-pass CSRR/RF-MEMS unit-cell with relevant dimensions. The slot regions of the CPW and the RF-MEMS are depicted in grey and black, respectively.

Fig. 2. 3D layout of a 2-stages band-pass filter based on the proposed CSRR/RF-MEMS unit-cell.

Fig. 3. Lumped-element equivalent-circuit of the unit-cell illustrated in Fig. 1.

Fig. 4. Insertion losses comparison between the electromagnetic simulation and the electrical model response of the unit-cell illustrated in Fig. 1.

Fig. 5. Return losses comparison between the electromagnetic simulation and the electrical model response of the unit-cell illustrated in Fig. 1.

Fig. 6. Insertion losses comparison between the electromagnetic simulation and the electrical model response of the 2-stages band-pass filter illustrated in Fig. 2.

Table I Equivalent circuit model parameters. 
Figure 1

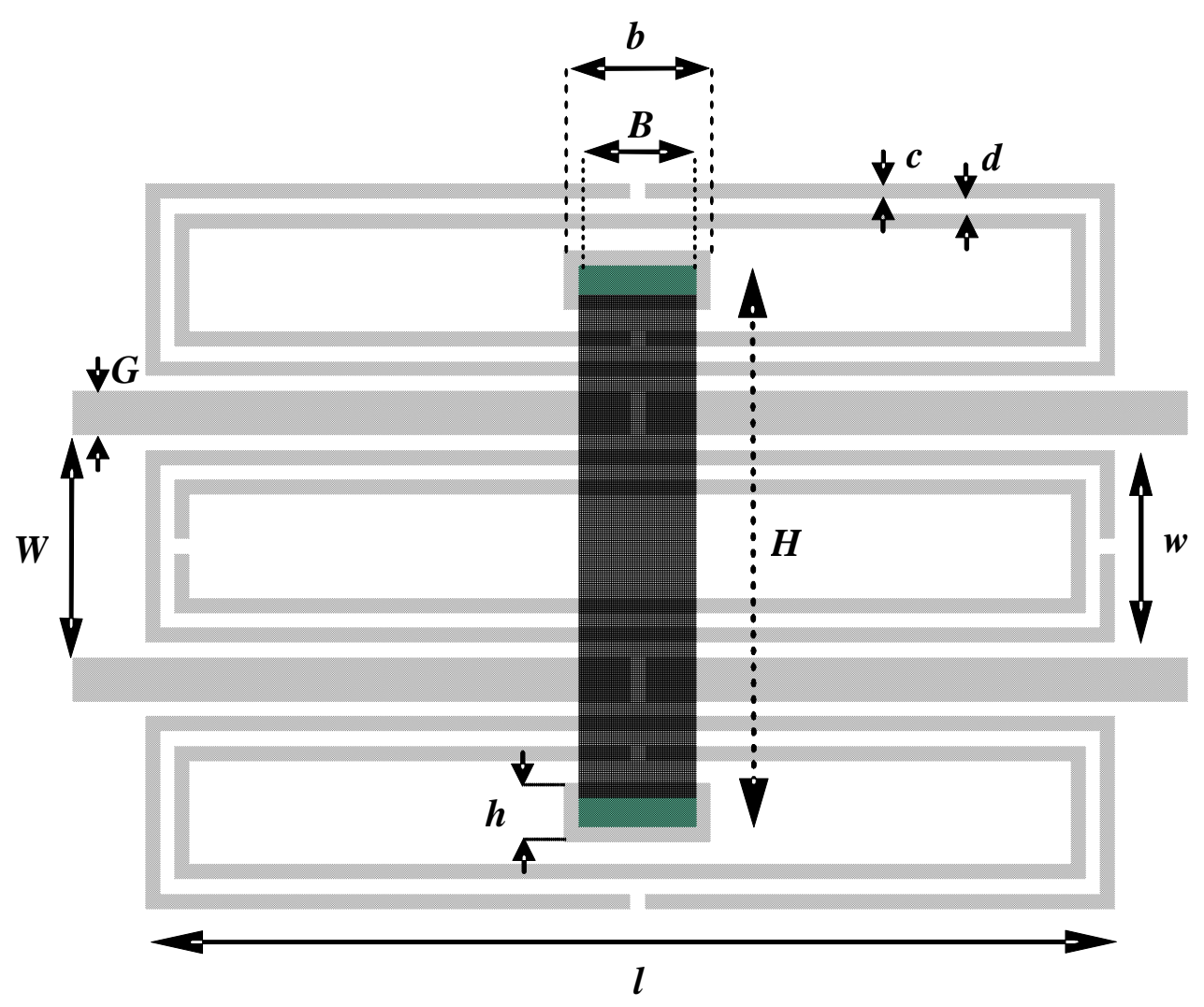


Figure 2

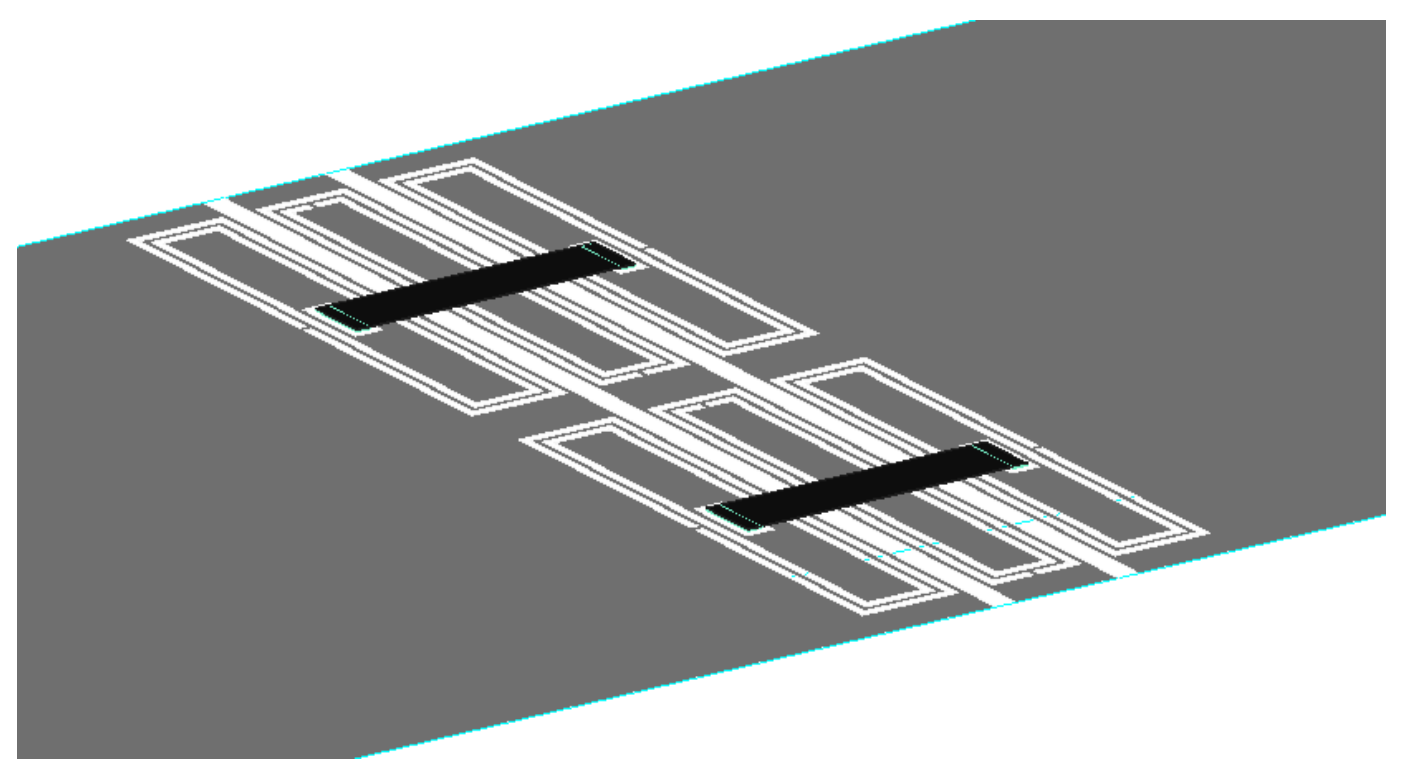


Figure 3

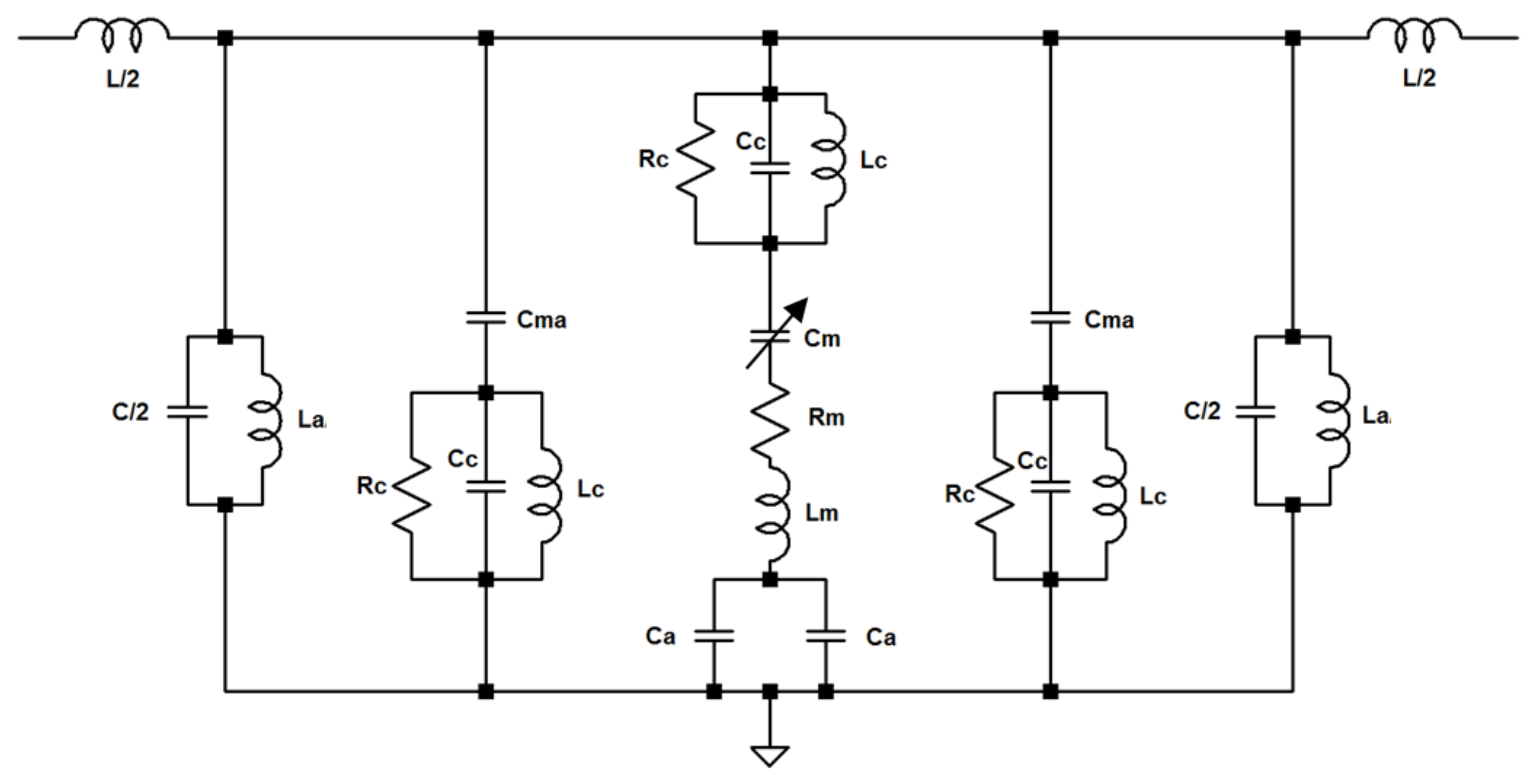


Figure 4

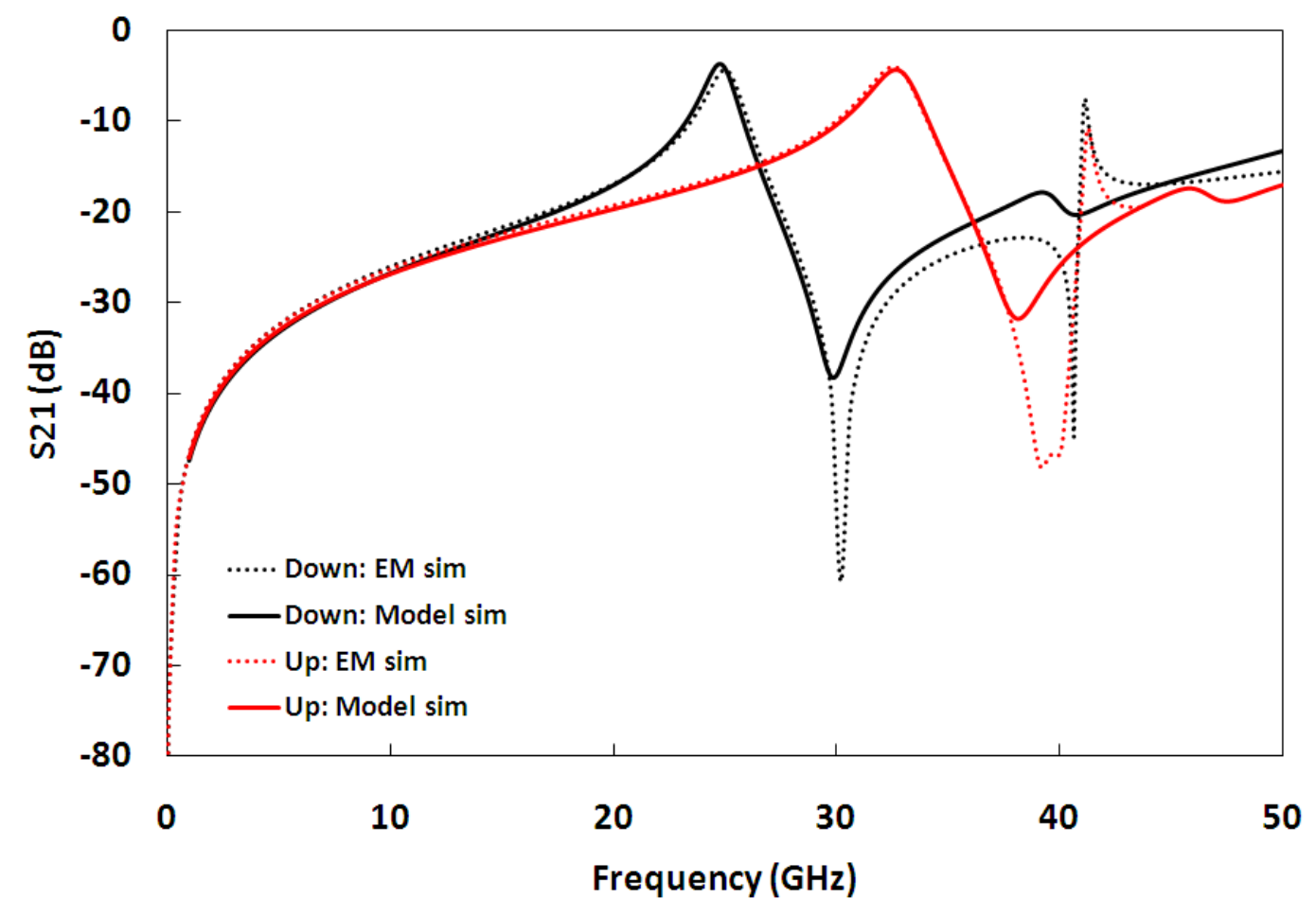


Figure 5

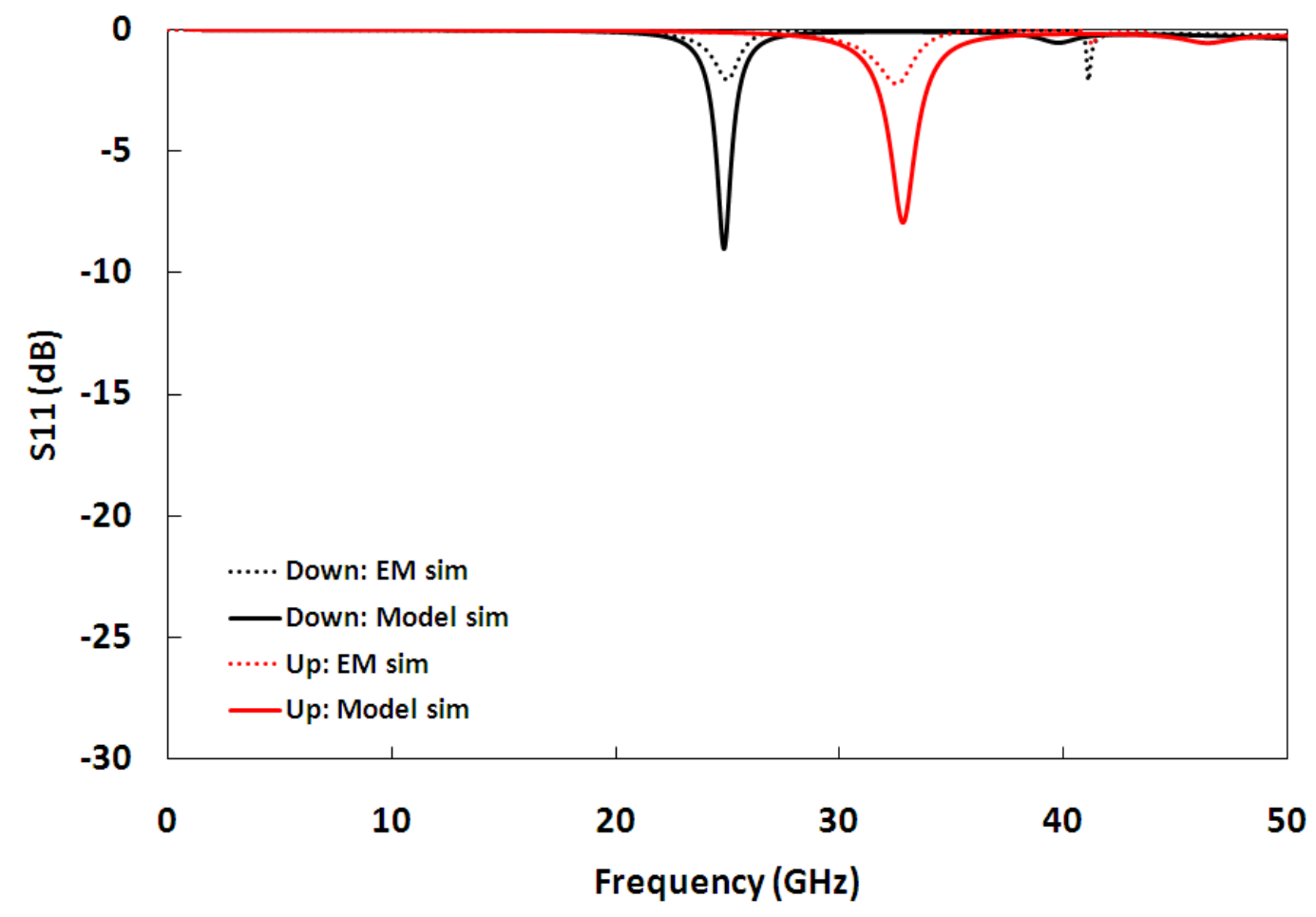


Figure 6

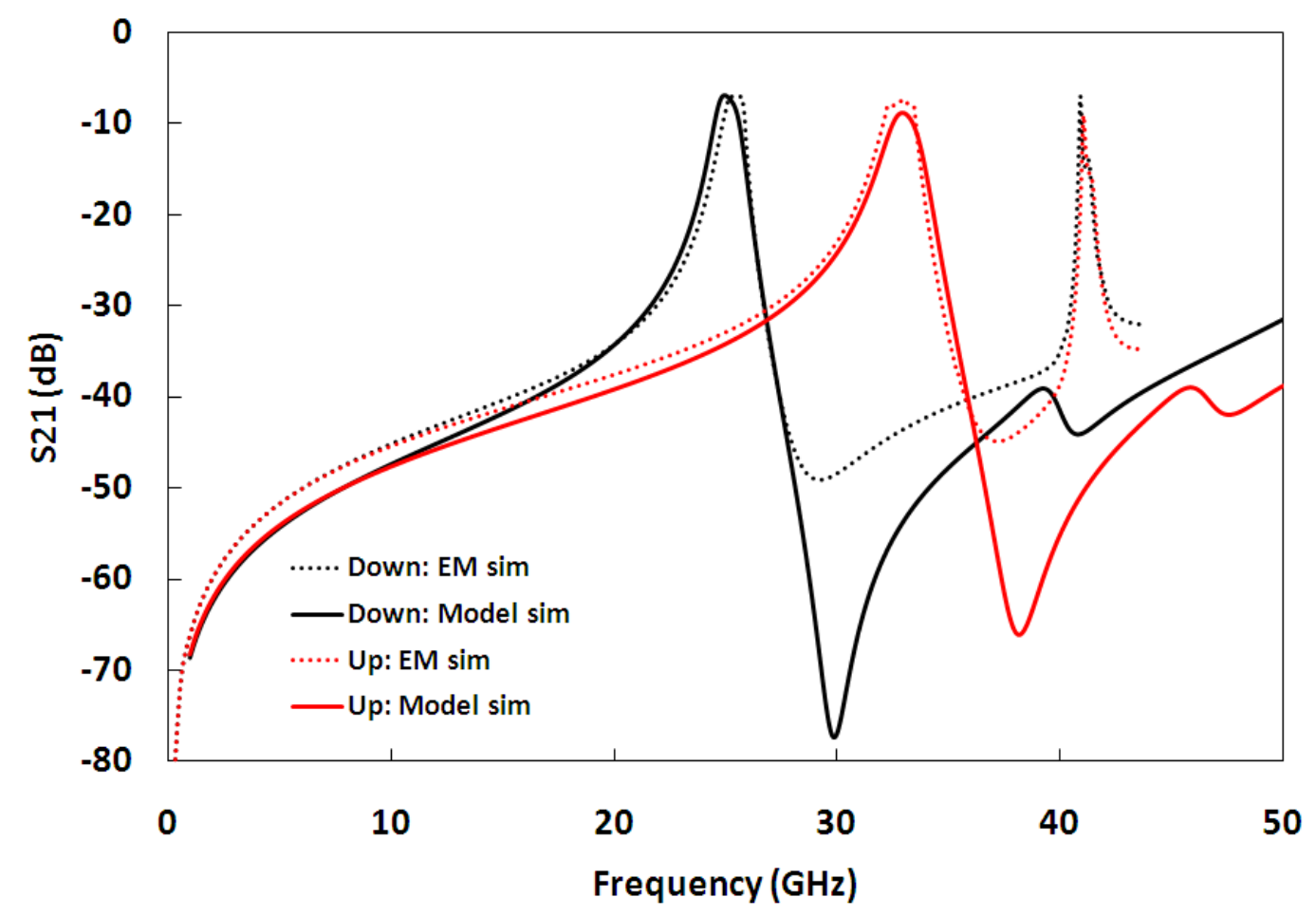




\section{Table I}

A stage band pass filter parameters

\begin{tabular}{|c|c|c|c|c|c|c|c|c|c|c|c|c|c|}
\hline $\begin{array}{c}\mathrm{L} \\
(\mathrm{pH})\end{array}$ & $\begin{array}{c}\mathrm{C} \\
(\mathrm{fF})\end{array}$ & $\begin{array}{c}\mathrm{L}_{\mathrm{a}} \\
(\mathrm{pH})\end{array}$ & $\begin{array}{c}\mathrm{C}_{\mathrm{maU}} \\
(\mathrm{pF})\end{array}$ & $\begin{array}{c}\mathrm{C}_{\mathrm{maD}} \\
(\mathrm{pF})\end{array}$ & $\begin{array}{c}\mathrm{L}_{\mathrm{M}} \\
(\mathrm{pH})\end{array}$ & $\begin{array}{c}\mathrm{C}_{\mathrm{MU}} \\
(\mathrm{fF})\end{array}$ & $\begin{array}{c}\mathrm{C}_{\mathrm{MD}} \\
(\mathrm{fF})\end{array}$ & $\begin{array}{c}\mathrm{R}_{\mathrm{M}} \\
(\Omega)\end{array}$ & $\begin{array}{c}\mathrm{L}_{\mathrm{C}} \\
(\mathrm{pH})\end{array}$ & $\begin{array}{c}\mathrm{C}_{\mathrm{CU}} \\
(\mathrm{fF})\end{array}$ & $\begin{array}{c}\mathrm{C}_{\mathrm{CD}} \\
(\mathrm{fF})\end{array}$ & $\begin{array}{c}\mathrm{R}_{\mathrm{C}} \\
(\Omega)\end{array}$ & $\begin{array}{c}\mathrm{C}_{a} \\
(\mathrm{pF})\end{array}$ \\
\hline 163 & 65 & 34 & 0.26 & 0.50 & 38 & 67 & 109 & 0.5 & 33 & 0.27 & 0.35 & 170 & 0.4 \\
\hline
\end{tabular}




\section{BRIEF BIOGRAPHIES}

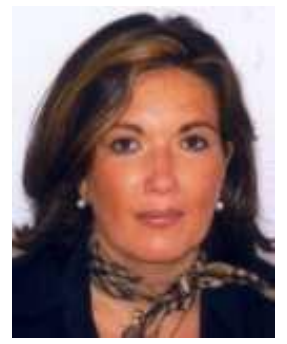

Marta Morata was born in Zaragoza, Spain on April 30, in 1970. She received her M.Sc degree in Physics with specialization within Optics from the Universidad de Zaragoza in 1994, and her $\mathrm{PhD}$ degree in Electronic Engineering from the Universitat Autònoma de Barcelona, Spain in 2004. From 2000 to 2004, she was with the National Centre of Microelectronics (CNM-CSIC), Barcelona where she developed her thesis. The topic of the PhD Thesis was the development of Microelectromechanical (MEMS) structures for gas detection. From 2004 to 2009, she was part time Assistant Professor in the Electronics Engineering Departament, Universitat Autònoma de Barcelona, Spain. In 2008, she joined as Titular Professor in Escuela Universitaria Salesiana de Sarriá (EUSS). Since 2009, she joined UPC emerging research group. Actually, her interests are RF microwave devices and circuits combining MEMS and metamaterials.

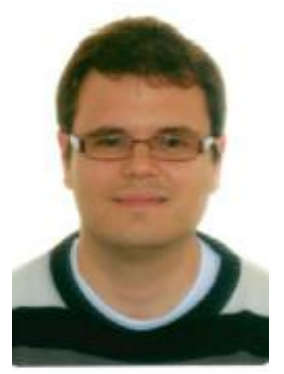

Ignacio Gil was born in 1978 in Barcelona, Spain. He received degrees in physics and electronics engineering in 2000 and 2003, and then his $\mathrm{PhD}$ in 2007 from the Universitat Autònoma de Barcelona, Spain.

From 2003 until 2008 he was Assistant Lecturer in Electronics and a researcher with the RF-Microwave Group in the Electronics Engineering Department, Universitat Autonòma de Barcelona, Spain. From 2006 until 2008 he worked for EPSON Europe Electronics $\mathrm{GmbH}$ where he developed high-performance integrated RF CMOS circuits, transceivers and system design. In 2008 he joined the Electronics Engineering Department, Universitat Politècnica de Catalunya, Spain, as lecturer and researcher. In recent years, he has been involved in different research activities including passive and active RF and microwave devices and circuits, metamaterials and EMC.

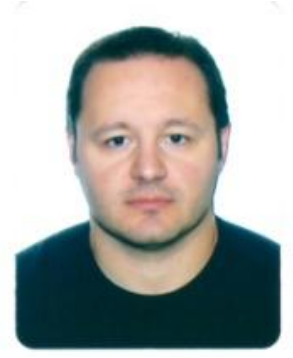

Raúl Fernández-García (M'06) was born in 1975 in Barcelona, Spain. He received degrees in telecommunications and electronics engineering in 1997 and 1999, and then his PhD in 2007 from the Universitat Autònoma de Barcelona, Spain. From 1998 until 2001 he worked for SONY España as an RF Engineer, where he developed analog and digital TV tuners. From 2001 until 2007 he was part time Assistant Lecturer in Electronics in the Electronics Engineering Department, Universitat Autonòma de Barcelona, Spain. In 2008 he joined the Electronics Engineering Department, Universitat Politècnica de Catalunya, Spain as a lecturer and researcher. In recent years, he has been involved in different 
research activities in the CMOS reliability field. Currently, he is involved on EMC robustness of integrated circuits. 